\title{
Influence of moisture on crack propagation in coal and its failure modes
}

DOI:

10.1016/j.enggeo.2019.105156

\section{Document Version}

Accepted author manuscript

Link to publication record in Manchester Research Explorer

\section{Citation for published version (APA):}

Yao, Q., Chen, T., Tang, C., Sedighi, M., Wang, S., \& Huang, Q. (2019). Influence of moisture on crack propagation in coal and its failure modes. Engineering Geology, 258, [105156]. https://doi.org/10.1016/j.enggeo.2019.105156

\section{Published in:}

Engineering Geology

\section{Citing this paper}

Please note that where the full-text provided on Manchester Research Explorer is the Author Accepted Manuscript or Proof version this may differ from the final Published version. If citing, it is advised that you check and use the publisher's definitive version.

\section{General rights}

Copyright and moral rights for the publications made accessible in the Research Explorer are retained by the authors and/or other copyright owners and it is a condition of accessing publications that users recognise and abide by the legal requirements associated with these rights.

\section{Takedown policy}

If you believe that this document breaches copyright please refer to the University of Manchester's Takedown Procedures [http://man.ac.uk/04Y6Bo] or contact uml.scholarlycommunications@manchester.ac.uk providing relevant details, so we can investigate your claim.

\section{OPEN ACCESS}




\title{
Influence of moisture on crack propagation in coal and its failure modes
}

\author{
Qiangling Yao ${ }^{1,2}$, Tian Chen ${ }^{1,2,3^{*}}$, Chuanjin Tang ${ }^{1,2}$, Majid Sedighi ${ }^{3}$, Songwei Wang ${ }^{1,2}$, Qingxiang Huang ${ }^{4}$, \\ 1. Key Laboratory of Deep Coal Resource Mining, Ministry of Education, Xuzhou, Jiangsu 221116, China; \\ 2. School of Mines, China University of Mining and Technology, Xuzhou, Jiangsu 221116, China; \\ 3. School of Mechanical, Aerospace and Civil Engineering, The University of Manchester, Manchester, M13 9PL, UK \\ 4. School of Energy and Resource, Xi'an University of Science and Technology, Xi'an, Shaanxi 710054, China
}

\begin{abstract}
Understanding of effects of water on crack propagation and crack failure modes of coal is important to determine the required width of the coal pillars in underground reservoirs and calculate the area of fractured zones containing flowing water. In this paper, we apply acoustic emission (AE) techniques, X-ray diffraction (XRD), scanning electron microscopy (SEM) and mercury intrusion porosimetry (MIP), alongside uniaxial compressive tests to develop new insights into the mechanics of crack developments and failure modes of partially saturated coal samples with a range of moisture contents $(0 \%, 6.00 \%, 9.75 \%$, and $10.96 \%)$. We present new relationships between tensile/shear cracks and failure modes incorporating the effects of water intrusion on the micro-tensile/shear cracks and macro tensile/shear failure modes.

The results show that the presence of hydrophilic illite (clay mineral) has strong influence on water absorption capacity of coal. The uniaxial compressive tests carried out in this study, show that the AE activity is mainly appeared after the crack damage threshold (point D) and it is independent to water content. The AE activity decreases with increasing moisture content as the water reduces the internal connections between the coal particles and increases the possibility of sliding failure. Studying the RA (rise time divided by peak amplitude) and $\mathrm{AF}$ values (counts divided by duration) demonstrated that the cracks generated in the coal samples consist of a large number of micro tensile and shear cracks, whilst tensile- or shear-only cracks were not found to be evident. For the samples studied, the higher moisture content is associated with the lower AF and higher RA values. Under the scope of the experimental investigations, we conclude that the higher moisture content corresponds to a lower number of total cracks and tensile cracks in coal. However, a greater proportion of shear cracks can be created by the increasing water content. Increasing the water level can reduce the number of tensile failure planes and the percentage of tensile failure planes against total failure planes. Therefore, the higher water content can increase shear failure planes and promote the possibility of shear failure in coal.
\end{abstract}

Keywords: moisture content; crack propagation; failure modes; coal; acoustic emission 


\section{Introduction}

Exploiting underground coal can affect adversely the water resources in mining regions. Mining activities can damage the water-resisting layers and the structure of aquifers by inducing deformations in the overlying strata. These effects can subsequently create potential for groundwater loss, river drying and other environmental problems. At present, approximately $70 \%$ of the coal resources in China are located in the arid middle-west region of China. Fig. 1a shows the location of major coal resources in China which are located in arid to semi-arid middle-west of the country where protection of the water resources is critically important (NDRC and NEB 2016). In a global scale, mining activities are extending to the regions, where protection measures of water resources may limit to large-scale mining. In recent years, water-conservation mining (as shown in Fig. 1b) and underground reservoir techniques ( Fig. 1c) have been introduced to mitigate the potential damages to water resources in arid regions.

In order to develop and improve sustainable approaches and techniques to mining, understanding of the effects of water on physical and mechanical properties of coal is critical. Previous research has mainly focused on the impact of water on the mechanical characteristics of coal (Huang and Liu 2013; Vishal et al. 2015; Yao et al. 2015); the influence of water on crack propagation or applied acoustic emission (AE) techniques to explore the effects of water on coal failure modes (Yao et al. 2016). Crack propagation and failure modes of coal are strongly associated with the permeability and mechanical properties of coal. These properties are used in engineering analysis of the construction of underground reservoirs or the excavation and stability of access paths/tunnels in coal seams. Therefore, studies related to the effects of water intrusion and stress on crack development and coal failure are highly important and largely missing in the existing literature.

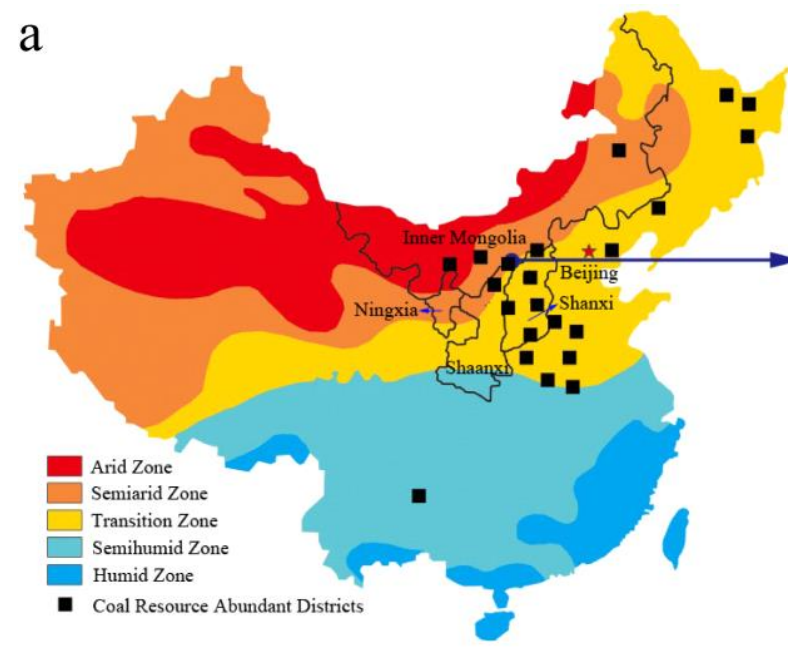

$\mathrm{b}$

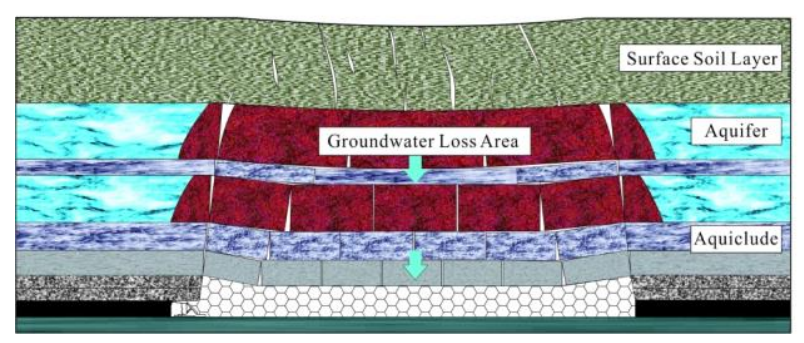

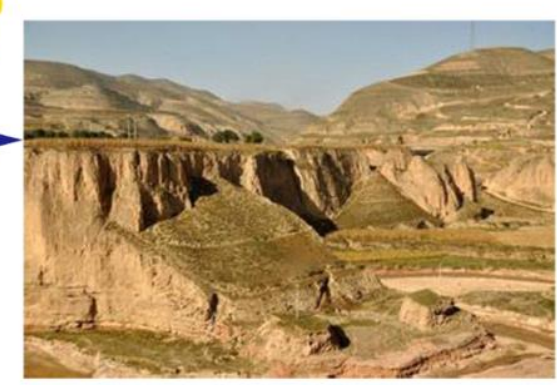

C

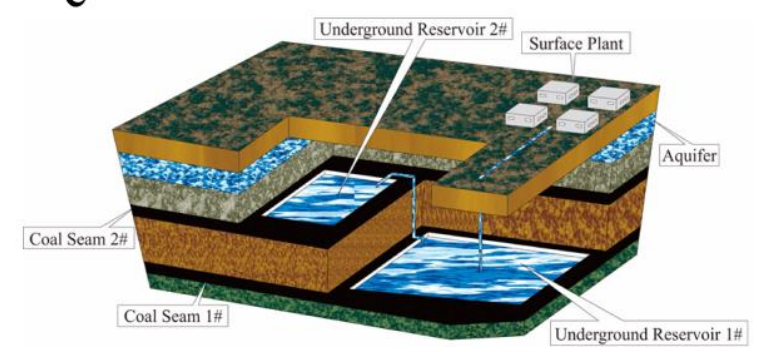


Fig. 1 (a) Distribution of Chinese water and coal resources, (b) Damage characteristics of overlying strata, (c) 3-D schematic of underground coal reservoir.

A number of research studies have contributed to the definition of crack development in the domain of rock mechanics. Hoek and Bieniawski (1965) have classified the crack propagation process into five phases based on the uniaxial compressive stress-strain curve and lateral strain for brittle materials (i.e. crack closure, elastic deformation, stable crack development, unstable crack propagation, and post-peak phases). These phases of crack propagation can be defined by various methods such as axial stiffness, stress-strain curves, volumetric stiffnessstress curves, and AE techniques (Eberhardt et al. 1998; Ranjith et al. 2008). Figure 2 illustrates the typical phases of crack propagation (Martin 1993). As illustrated in Fig. 2, macro-crack planes only occur after crack coalescence (stage IV, shaped with yellow color) and cracks that occur in stages I, II, and III are micro-cracks, which are not visible to the naked eye (Eberhardt et al. 1998).

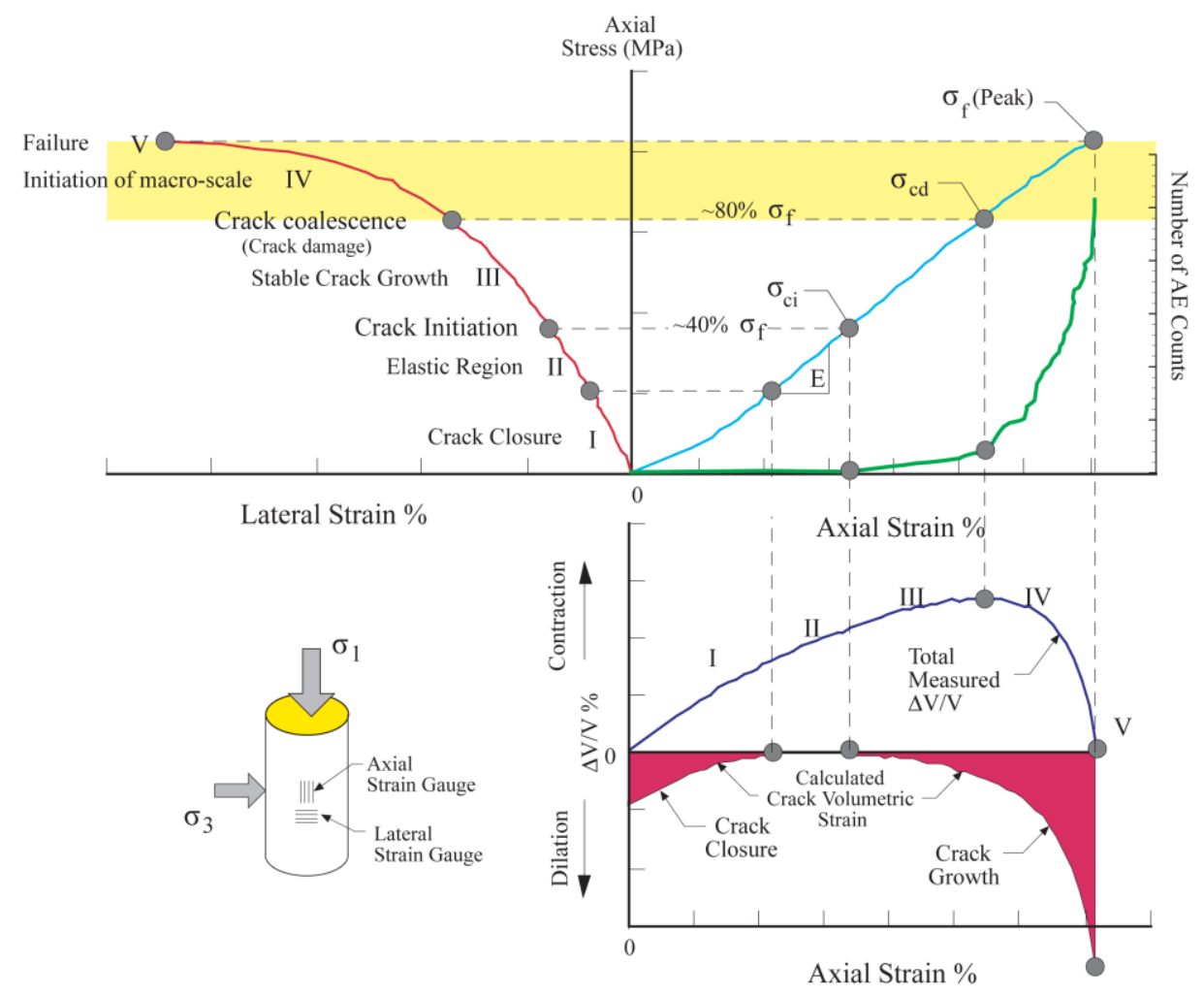

Fig. 2 Typical stress versus strain variations for rocks based on observations via strain and acoustic emissions.

Using AE techniques and volumetric strain, Eberhardt et al. (1998) studied the impact of water on crack closure and propagation in brittle rocks. Ranjith et al. (2008) have found that the fully saturated concrete samples are to be weaker than dry samples. They have also shown (based on uniaxial compression tests) that the elastic modulus and Poisson's ratio increases in response to the increase in moisture content. It was also reported that the moisture content has slight effects on crack initiation and damage thresholds in concrete. Based on AE measurements; Chen et al. (2014) and Meng et al. (2014) have shown that the brittleness can affects the stress drop in rocks during the post-peak phase of stress-strain behavior . Khazaei et al. (2015) utilized the AE technique to describe the fracture plane propagations. Lyu et al. (2015) reported the main phases of crack propagation in shale (based on AE measurements) and reported that energy released during unstable crack propagation. Acoustic 
emission methods (such as rise time, count, amplitude and duration) are frequently used to classify and examine the location of cracks in materials. The most important parameters for classifying crack types are RA (which is defined by RA = rise time/amplitude) and the average frequency (AF), described as counts/duration.

Grosse and Ohtsu (2008) and Committee (2010) define "amplitude" as the largest amplitude in a waveform and the rise time as the time duration between the first signal and peak amplitude. Duration is the time between the first and last point at which a hit crosses a threshold, and count is the number of times at which the signal amplitude exceeds the threshold (Fig. 3a). The average frequency which is measured in $\mathrm{kHz}$, is the count divided by the duration, and RA is the rise time divided by peak amplitude ( $\mu \mathrm{s} / \mathrm{v}$ or ms/v). Cracks are classified as tensile or shear as shown in Fig.3 which is based on the relationship between the AF and RA (Aggelis 2011; Kordatos et al. 2012; Ohno and Ohtsu 2010; Ohtsu et al. 2007). The shear cracks occur when the AE signal has a high RA but low AF value, whereas tensile cracks occur when the AE signal has a low RA and AF value. In Fig. 3c, the region above the diagonal corresponds to tensile cracks, and the region below the diagonal corresponds to shear cracks. This relationship is based on a large number of experimental studies and statistical analysis, which has been standardized by the academic community (Committee 2010; Grosse and Ohtsu 2008).

\section{a}

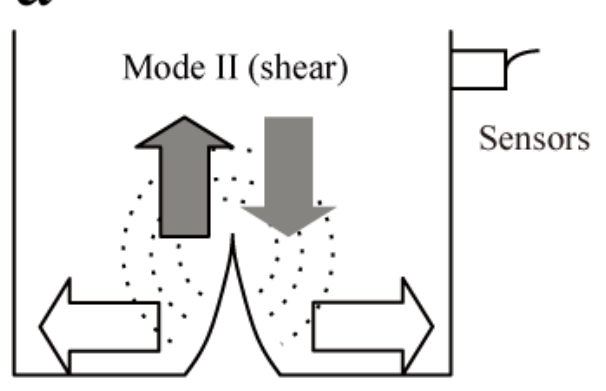

Mode I (tensile)
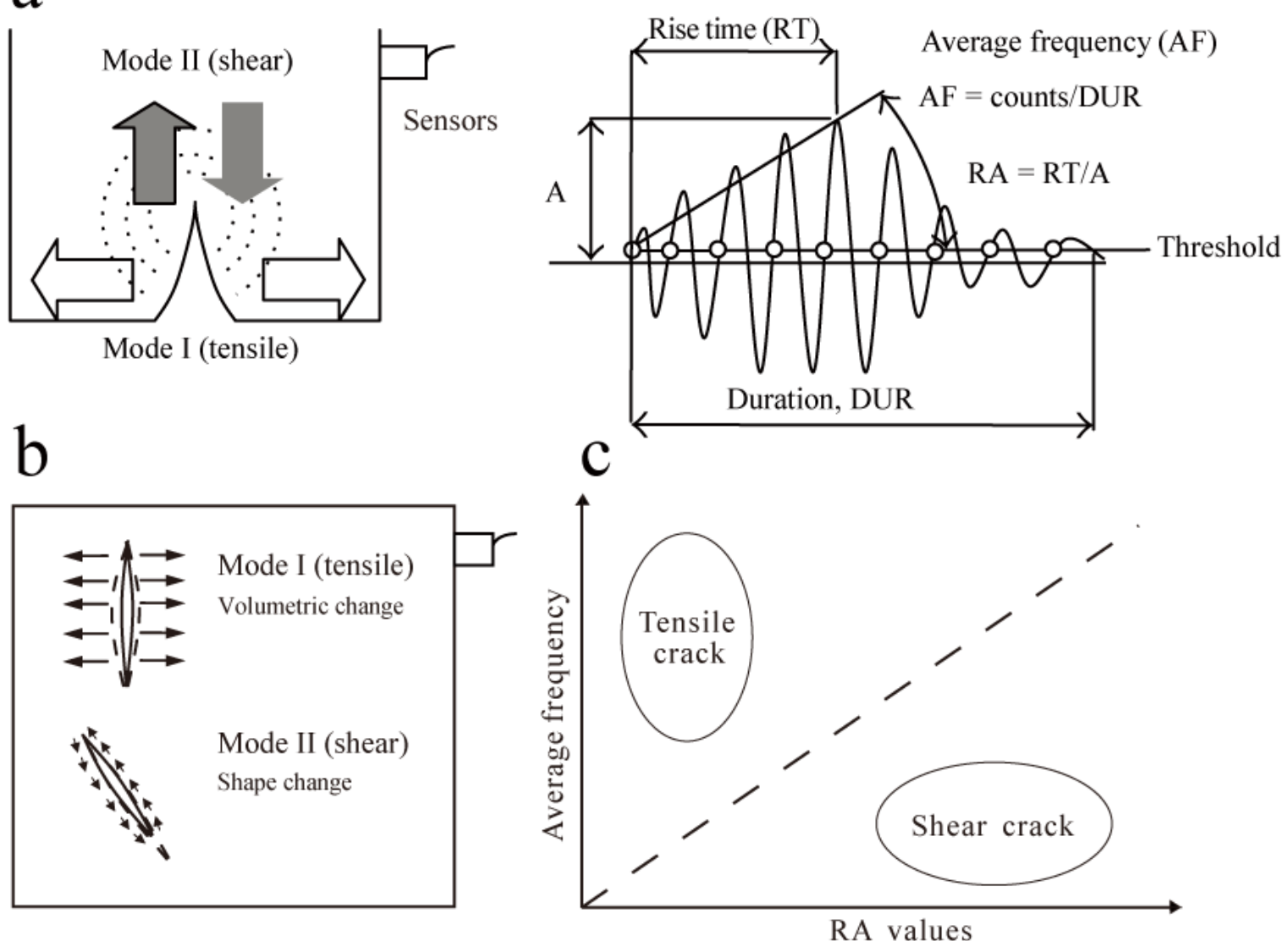

Fig. 3 Typical AE waveform and micro fracture (cracks) classification

The AE techniques have been used to classify the crack modes and material failure modes. Aggelis et al. (2011) utilized the AE to monitor changes in the tensile and shear cracks during metal fatigue damage to predict the final failure mode of metal. Nor et al. (2013) described an analysis of crack types in a specimen under stress using AE methods and demonstrated that the AF and RA methods can be successfully used to determine crack 
types and tendencies. Aggelis et al. (2012) illustrated macro- and micro-crack propagation paths in cementitious materials and found that the relationship between AF and RA reflected accurately the path. According to Woo et al. (2014), AF and RA measurements can provide information on the relationship between the fracture processes and damage mechanisms of structural materials to be used as an early warning of final material failure modes. (Farhidzadeh et al. 2014; 2013) reported that the tensile cracks in fracturing cement emitted higher RA and lower AF values compared with the shear cracks. Kencanawati et al. (2012) reported formation of both tensile and shear cracks using $\mathrm{AE}$ techniques for different concrete types exposed to $1 / 3$ stress levels. Tensile cracks are found to be more likely to occur under $2 / 3$ stress levels, but both tensile and shear cracks increased significantly under the maximum stress levels as concrete approaches failure. Based on the distribution of AE signals, He et al. (2015) and He et al. (2012) showed that the rockbursts could produce a large number of tensile and shear cracks; the AE signal decreased with unloading rate due to the considerable decrease in the number of cracks. Masahiro et al. (1988) suggested that the AE location occurred along the cracks with a striped distribution. Mogi (2007) used a self-made triaxial machine to study the influence of intermediate principal stress on rock failure modes. In summary, the majority of previous studies have used AE techniques to analyze crack types in concrete and metals, but relatively few have investigated crack modes in coal or the influence of water on these processes because of the heterogeneity and anisotropy of coal.

As shown in Fig. 4a, four major types of failure mechanisms in rock in response to uniaxial compressive stress have been identified (Jaeger et al. 2009; Peng 2013). In Fig. 4a, failure modes I and II/III occur when shear stress exceeds the ultimate stress on the failure surface, which creates micro cracks to develop and coalesce on the macro-shear plane. Therefore, these three failure modes are defined as shear failure. For another (i.e. mode IV), the effect of uniaxial stress on rock samples contributes to the tensile stress, and consequently, the lateral stress may exceed the compressive strength and result in failure. This type of failure (mode IV) is caused by tensile stress and is the result of Poisson's effect; it is worth noting that numerous tensile-shear cracks in coal and even in denser rock (e.g. marble) are not visible by the naked eye (Yang et al. 2017). As demonstrated in Fig. 2, a crack only becomes visible on the macro-scale after crack coalescence, after which it eventually develops into a tensile or shear failure plane (Fig. 4a). Figure $4 \mathrm{~b}$ shows experimental tensile or shear failure planes (marked as T or S) (Cho et al. 2007). Failure of coal samples can be caused by both tensile failure planes and shear failure planes (Fig. 4b). As shown in Fig. 4c, micro-propagations spread and develop into larger cracks. According to Cho et al. (2007), rocks can be modeled as particles: "As rock is subjected to deviatoric stresses, local tensile stress will be generated because of the heterogeneous nature of the rock." Thus, the local extension and shearing action between particles leads to bigger cracks, which coalesce to form a macro-failure plane (Fig. 4b). 
a
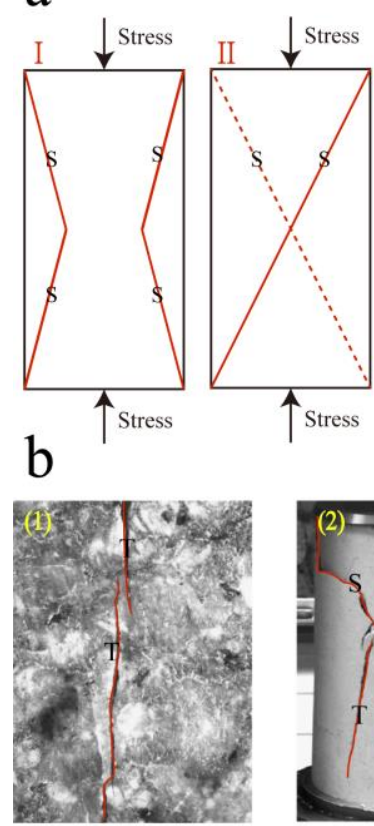
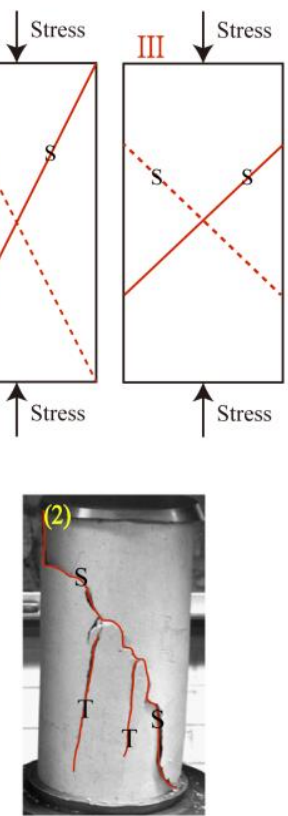

C
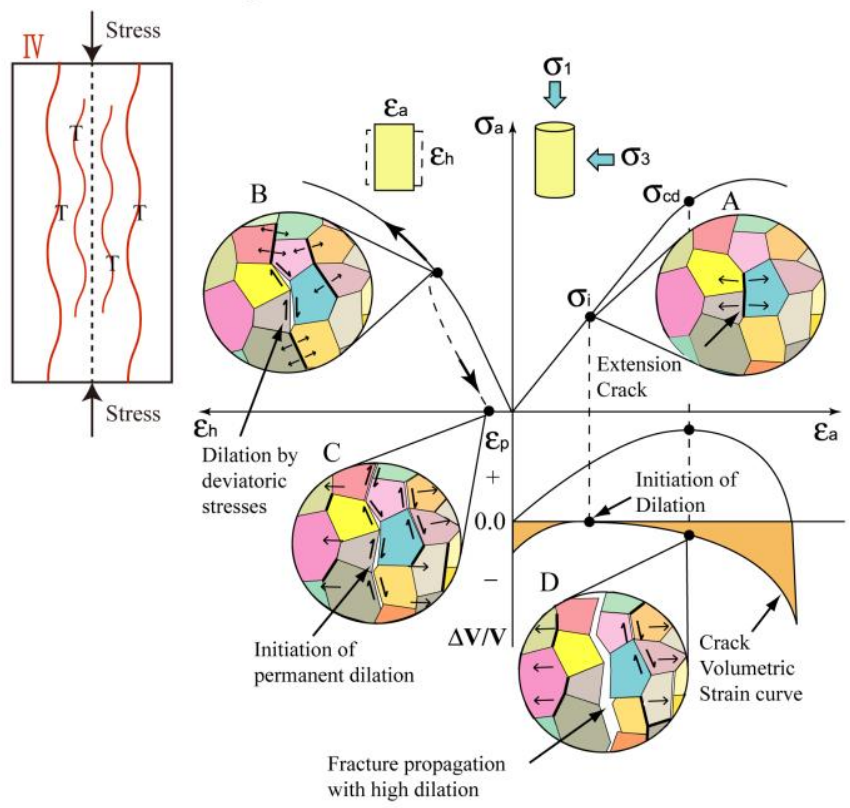

Fig. 4 (a) Failure modes: I) X-shaped conjugate shear failure; II and III) single-plane shear failure; IV) tensile failure (Jaeger et al. 2009; Peng 2013); (b) failure planes caused by uniaxial compression (Cho et al. 2007); (c) dilation due to fracture initiation and growth in brittle material subjected to compressive loading (Cho et al. 2007).

In this study, we used a water-intrusion device to determine the relationship between moisture content and intrusion time. The function curve between the water content and time was used to identify four typical intrusion time points and predict moisture content. Uniaxial compressive tests were conducted on four groups of coal samples (12 standard coal specimens). X-ray diffraction (XRD) was used to analyze the inorganic mineral content of the coal samples, scanning electron microscopy (SEM) was employed to observe microstructures on the coal surface, and mercury intrusion porosimetry (MIP) was used to determine porosity. We separated crack propagation into five stages based on the relationship between cumulative counts and stress, and explored how cumulative counts varied in samples with different moisture contents. AF and RA were introduced to demonstrate the effect of water on tensile-shear crack propagation and coal failure processes.

Section 2 describes the experimental program and methods applied. Development of the experimental setup used in this study is summarized in section 2.1. Sample preparations and water intrusion tests are described in sections 2.2 and 2.3, respectively. AE experimental method and protocol is described in Section 2.4. Section 3 described the effects of water on crack propagation (3.1), on micro-tensile/shear cracks (3.2) and on macro-tensile /shear failure modes (3.2).

\section{Experimental program and material characterization}

\subsection{Experimental setup summary}

The main components of the experimental setup used in this study include a wetting apparatus, loading system, and a digital strain data recorder (Fig. 5b)(Chen et al. 2017). The wetting apparatus is comprised of a humidifier which is connected to a sealed sample box with a plastic hose (Fig. 5b). The humidifier creates a 
high-moisture environment by generating mist which enters the sealed box through the hose. This method avoids the need for sample immersion, which can cause disintegration. An electronic universal testing machine operated by a microcomputer (No. CMT5305; San Si Co., Shenzhen, China) was used as the loading system. Static resistance strain indicators (model No. TS3890) consisting of digital strain gauges with microprocessor chips were attached to the surface of coal samples and connected to the main control computer (MCC). The MCC controls, processes, displays, and transmits measured data. The strain acquisition system collects multi-point strain values with high temporal frequency.

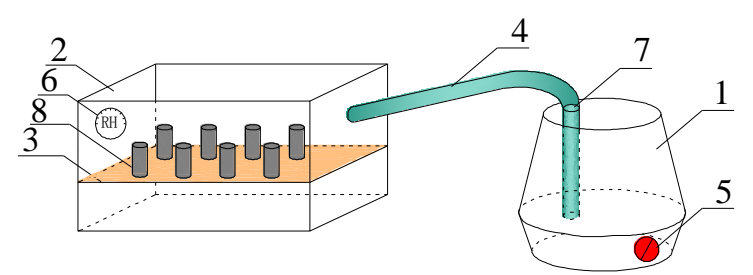

1-Humidifer; 2-Sealed box; 3-Water permeable board; 4-Plastic hose; 5-Power adjusting knob 6-Humidometer; 7-Water mist vent; 8-Coal specimens

(a) Water intrusion apparatus

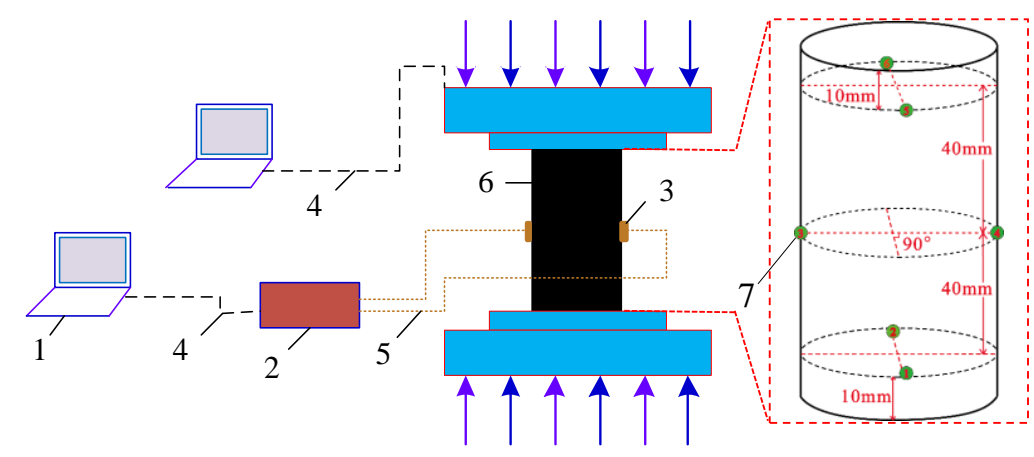

1-Main control computer; 2-Stain acquisition system; 3-Electric resistance strain gauge;

4-Data transmission line; 5-Wire; 6-Coal specimen; 7-AE Sensors

(b) Computer-aided testing system

Fig. 5 Schematic diagram of the experimental system used in this study

\subsection{Sample preparation}

To investigate the effects of water on crack propagation and failure processes of coal, we collected samples from coal seam \#2, which is located in a water-bearing excavated roadway at Xinqiao Colliery of the Yongcheng coal group (Yongcheng, Henan province). According to the requirements of the International Society for Rock Mechanics (Fairhurst and Hudson 1999), coal should be processed as $\varphi 50 \mathrm{~mm} \times \mathrm{H} 100 \mathrm{~mm}$ cylindrical samples. Based on SEM of four different points (Fig. 6), the coal samples had relatively flat and clean surfaces, low porosity, and few cracks relative to samples described in previous studies (Jones et al. 1992; Zygarlicke and Steadman 1990). Insufficiently developed protogenetic cracks (i.e., without full coalescence) were evident, and the samples showed relatively strong integrity. 
(1)

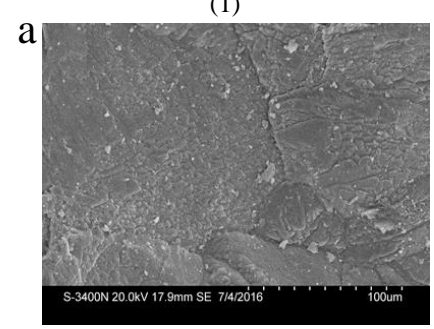

b

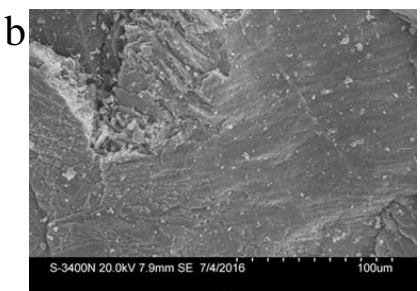

C
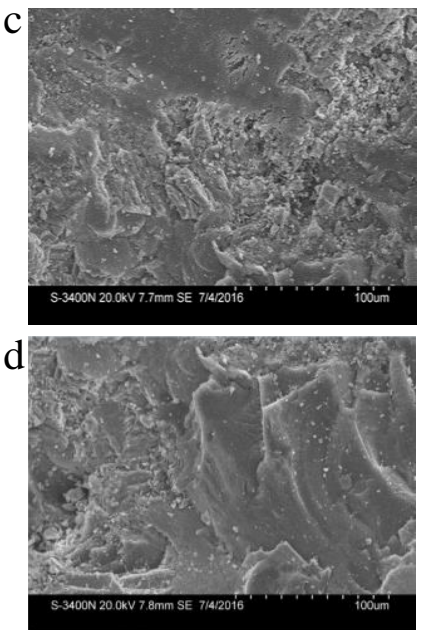

(2)
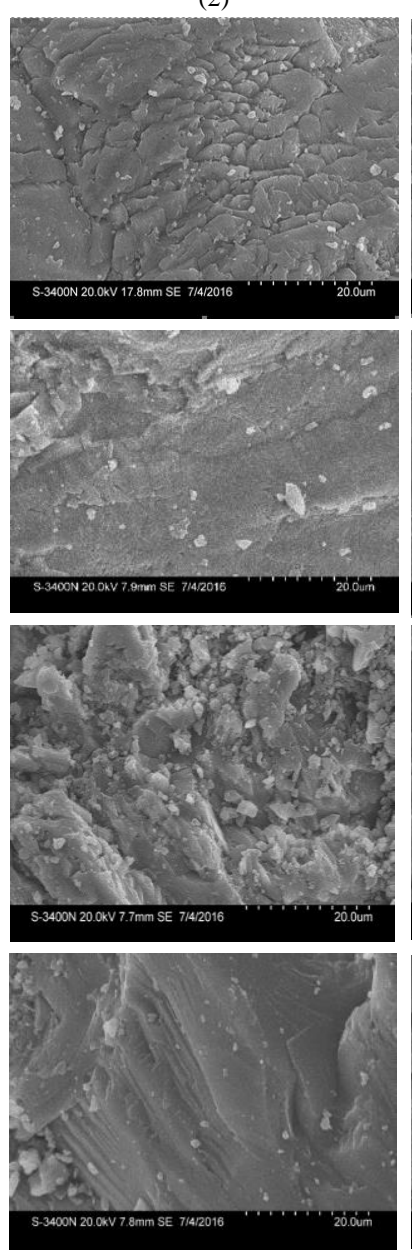

(3)
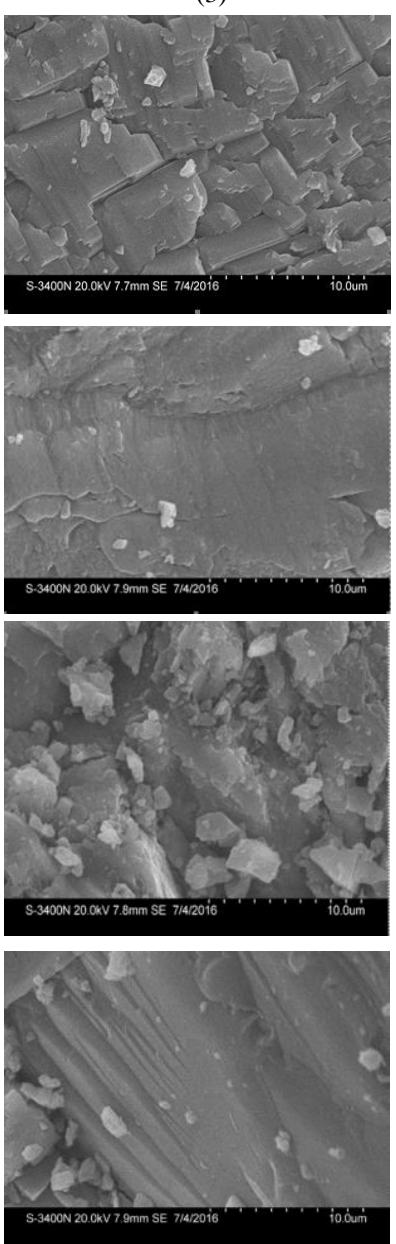

Fig. 6 Microscopic surface of samples

The mineral content of the coal was determined using XRD analysis (Fig. 7). The content of inorganic minerals was calculated by spectrum fitting using MDI Jade6.5 software (Table 1). Inorganic minerals consisted of calcite, dolomite, illite, and pyrite. According to Terzaghi et al. (1996), calcite is a stable mineral; the permeability of dolomite is higher than that of calcite, but dolomite is less stable than calcite. Illite is a typical clay mineral and in its dry condition, illite has strong hygroscopicity, whereas wet illite is malleable. Our coal samples have a high amount of illite, and thus are strongly hygroscopic and hydrophilic.

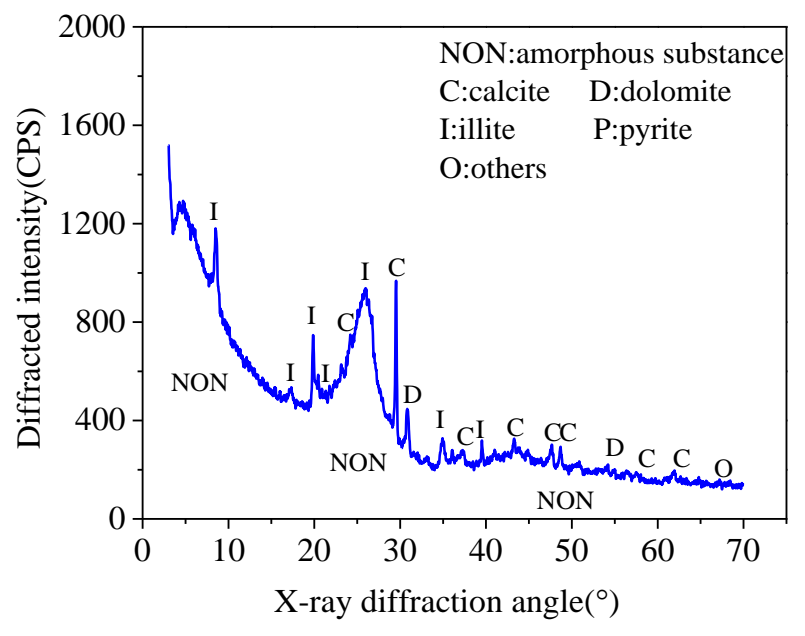

Fig. 7 XRD results of the coal samples 
Table 1 Composition of the inorganic minerals in coal

\begin{tabular}{cccccc}
\hline coal & Calcite & dolomite & illite & pyrite & Others \\
\hline Xinqiao coal 2\# & $57.4 \%$ & $20.3 \%$ & $15.6 \%$ & $3.5 \%$ & $3.2 \%$ \\
\hline
\end{tabular}

The internal porosity of coal samples was measured by the mercury intrusion porosimeter (No. AutoPore IV9510) and found to be $4.2 \%$ (Table 2), which is close to reported smallest values for coal by other researchers (Li et al, 2013). Coal has a higher porosity than most rocks. Coal typically contains numerous micro- and macro-pores, as well as cracks. Under stress, pores and cracks can open and connect, which facilitates water diffusion and transport.

Table 2 Results of MIP experiments

\begin{tabular}{|c|c|c|c|c|c|c|c|c|c|}
\hline \multirow{4}{*}{$\begin{array}{l}\text { Sample } \\
\text { weight } \\
\text { (g) }\end{array}$} & \multirow{3}{*}{$\begin{array}{l}\text { Total intrusion } \\
\text { volume }\end{array}$} & \multirow{3}{*}{$\begin{array}{l}\text { Total } \\
\text { Area }\end{array}$} & \multirow{3}{*}{ Pore } & \multirow{3}{*}{$\begin{array}{l}\text { Average Pore } \\
\text { Diameter }\end{array}$} & \multirow{3}{*}{$\begin{array}{l}\text { Bulk } \\
\text { Density }\end{array}$} & \multirow{2}{*}{$\begin{array}{l}\text { Apparent } \\
\text { (skeletal) }\end{array}$} & \multirow[b]{2}{*}{ Porosity } & \multirow[b]{2}{*}{ Permeability } & \multirow{3}{*}{$\begin{array}{l}\text { Threshold } \\
\text { Pressure }\end{array}$} \\
\hline & & & & & & & & & \\
\hline & & & & & & & & & \\
\hline & $(\mathrm{ml} / \mathrm{g})$ & $\left(\mathrm{m}^{2} / \mathrm{g}\right)$ & & $(\mathrm{nm})$ & $(\mathrm{g} / \mathrm{ml})$ & $\begin{array}{l}\text { Density } \\
(\mathrm{g} / \mathrm{ml})\end{array}$ & $(\mathrm{n} / \%)$ & $(\mathrm{k} / \mathrm{mD})$ & (psia) \\
\hline 1.8331 & 0.0313 & 11.84 & & 10.6 & 1.34 & 1.39 & 4.2 & 30.1 & 3.84 \\
\hline
\end{tabular}

\subsection{Water intrusion test}

Three equally-sized cylindrical coal samples were prepared and placed in the water intrusion apparatus until they became fully saturated with water. The samples were weighed at fixed intervals of 30 minutes, and the relationship between the water moisture content (average water absorption) and water-intrusion time was established (see blue points in Fig. 8).

The adsorption reaction rate at the water-rock interface can be described by a pseudo-first order kinetic model (see Equation (1) below) (Azizian 2004). Water intrusion of coal samples is an adsorption process that can be described by:

$$
\frac{d q_{t}}{d t}=k_{1}\left(q_{e}-q_{t}\right)
$$

where, $q_{e}$ and $q_{t}(\mathrm{~g} / \mathrm{g})$ are the adsorption capacity of the solute at equilibrium and at time $\mathrm{t}(\mathrm{h})$; and $k_{l}\left(\mathrm{~h}^{-1}\right)$ is the pseudo-first order kinetic adsorption rate constant. According to the boundary conditions $\left(t=0, q_{t}=0, t=t\right.$, and $q_{t}$ $\left.=q_{t}\right)$, the integral of the above formula yields:

$$
q_{t}=q_{e}\left(1-\mathrm{e}^{-k_{1} t}\right)
$$

Finally, the water intrusion model of coal can be derived as Equation (3).

$$
\omega_{t}=\omega_{e}\left(1-\mathrm{e}^{-k_{1} t}\right)
$$

Where, $t(\mathrm{~h})$ is the water intrusion time, $\omega_{t}$ is the corresponding moisture content, and $\omega_{e}$ is the water content at saturation

The relationship between moisture content and water intrusion time can be expressed as : 


$$
\omega_{t}=10.96\left(1-e^{-0.44 t}\right)
$$

As shown in Fig. 8, the moisture content increased nonlinearly with exposure time (intrusion time). The process can be divided into three stages: rapidly increasing, slowly increasing, and moisture saturation (stable stage). The rate of moisture absorption gradually decreased until the moisture content stabilized at $10.96 \%$, indicating water saturation.

We used Equation (4) to calculate the variations of moisture content with time. We selected four time intervals on the water-absorption curve $(0,1.8,5$, and 20 hours) covering the three stages (Fig. 8) and calculated the corresponding moisture content at these points $(0 \%, 6.00 \%, 9.75 \%$, and $10.96 \%$, respectively). Please note the maximum volumetric water content of samples is possibly higher than their total porosity because of some inevitable cracks in coal and no confining pressure during water intrusion process.

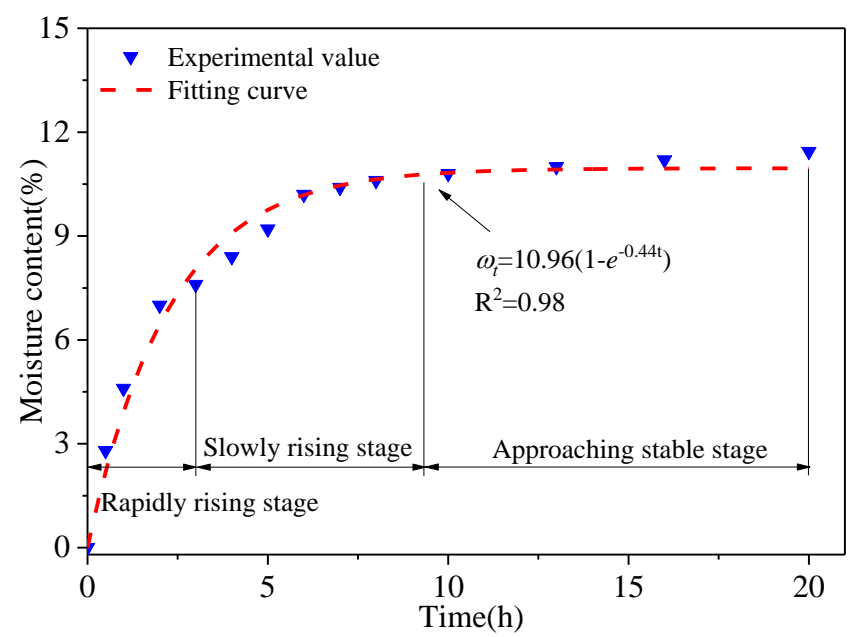

Fig. 8 Variations of moisture content with time (relationship between moisture content and water-intrusion time is shown)

\subsection{AE experimental methods}

After recording the initial weight of 12 coal samples, they were dried $\left(105^{\circ} \mathrm{C}\right.$ for 8 hours $)$ and kept in oven to avoid uptake of the atmospheric moisture. The water intrusion device was then used to increase the moisture content of the samples until the desired saturation level was reached. The samples were separated into four groups according to time spent in the device. The samples were then labeled $\mathrm{C} 1$ were not humidified $(0 \%$ water saturation), and samples C2-C4 were humidified for 1.8, 5, and $20 \mathrm{~h}(6.00 \%, 9.75 \%$, and $10.96 \%$ water saturation, respectively). The second number in each sample label (e.g., C1-1, C1-2, C1-3) designates sample replicates.

Uniaxial compression tests were performed on the coal samples, and AE data were recorded. Six AE sensors (Nano 30; PAC2; Physical Acoustics Corporation, Princeton, NJ, USA) were attached to the samples (Fig. 5b). The PAC2 parameters measured are as follows: i) operating frequency range of $125-750 \mathrm{kHz}$, ii) resonant frequency of $300 \mathrm{kHz}$, iii) threshold value of $40 \mathrm{~dB}$ and gain of $40 \mathrm{~dB}$, iv) analogue filter lower and upper limits of 1 and $400 \mathrm{kHz}$, respectively, and v) sampling frequency of $2 \mathrm{MHz}$. The loading (displacement) rate on the universal testing machine was $0.2 \mathrm{~mm} / \mathrm{min}$. During the tests, the AE system and universal testing machine logged data simultaneously. 


\section{Results and Discussion}

\subsection{Effects of water on crack propagation in coal}

Figure 9 shows the determination of the stress threshold based on the cumulative number of AE counts(using sample C1-1 as an example). Similar to the stress-strain curve, the cumulative number of AE counts generally increases with time and loading. During the crack closure (line segment A-B), there is relatively limited AE activity due to the existing micro cracks which creates signal negligibly. As the uniaxial load intensified, the AE counts slightly increase, indicating the start of the elastic deformation stage (segment $\mathrm{B}-\mathrm{C}$ ). The number of $\mathrm{AE}$ counts starts to linearly increase, marking the point of crack initiation (point $\mathrm{C}$ ) and the initiation of the stable crack propagation. The slope of the curve (C-D) gradually increases (i.e. larger AE counts) which indicates greater release of the strain energy. The crack damage starts when the curve departs from linearity to an exponential or the so-called power law response . Unstable crack propagation begins in this zone (D-E) and continues until failure of the specimen (point E) (Eberhardt et al. 1999; Ranjith et al. 2004). Point E is considered as the peak stress point which is followed by the post-peak stage.

The mechanical properties of the rock and the forms of crack growth vary between stable and unstable crack propagation stages. Stable crack propagation, characterized by the development of new micro cracks, is reversible (Eberhardt et al. 1998). If the load is removed, the rock or coal sample will return to its unloaded state. In contrast, during unstable crack propagation, internal macro cracks begin to form, which combine, extend, and ultimately approaches a size adequate to be observed by the naked eyes. If the rock is unloaded at this stage, it is still damaged and does not retain its original mechanical properties. For example, the strength of this type of unloaded coal samples is lower than that of a coal sample which has not experienced same level of stresses, even though the unloaded sample is still intact. Moreover, the cracks can only be observed by the naked eyes during or after the unstable crack propagation stage (after D).

Crack development and thresholds over time are illustrated in Fig. 9. All crack thresholds (i.e., crack closure, crack initiation, and crack damage thresholds) decrease with rising moisture content (Fig. 9). The peak stress and cumulative counts also decline, indicating that increasing water can increase plasticity and reduce elasticity, amount of energy released, and crack propagation intensity. These results are similar to those reported by Yao et al. (2016) using a different type of coal. 
a
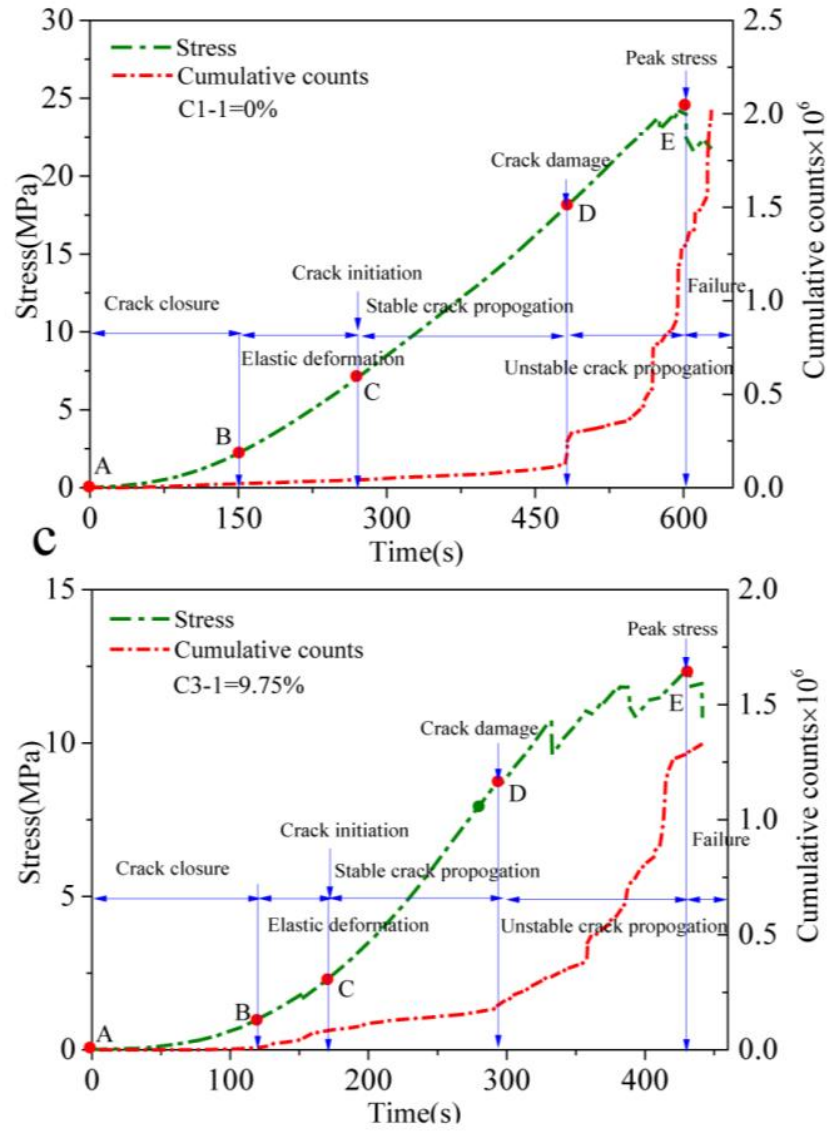

$\mathrm{b}$
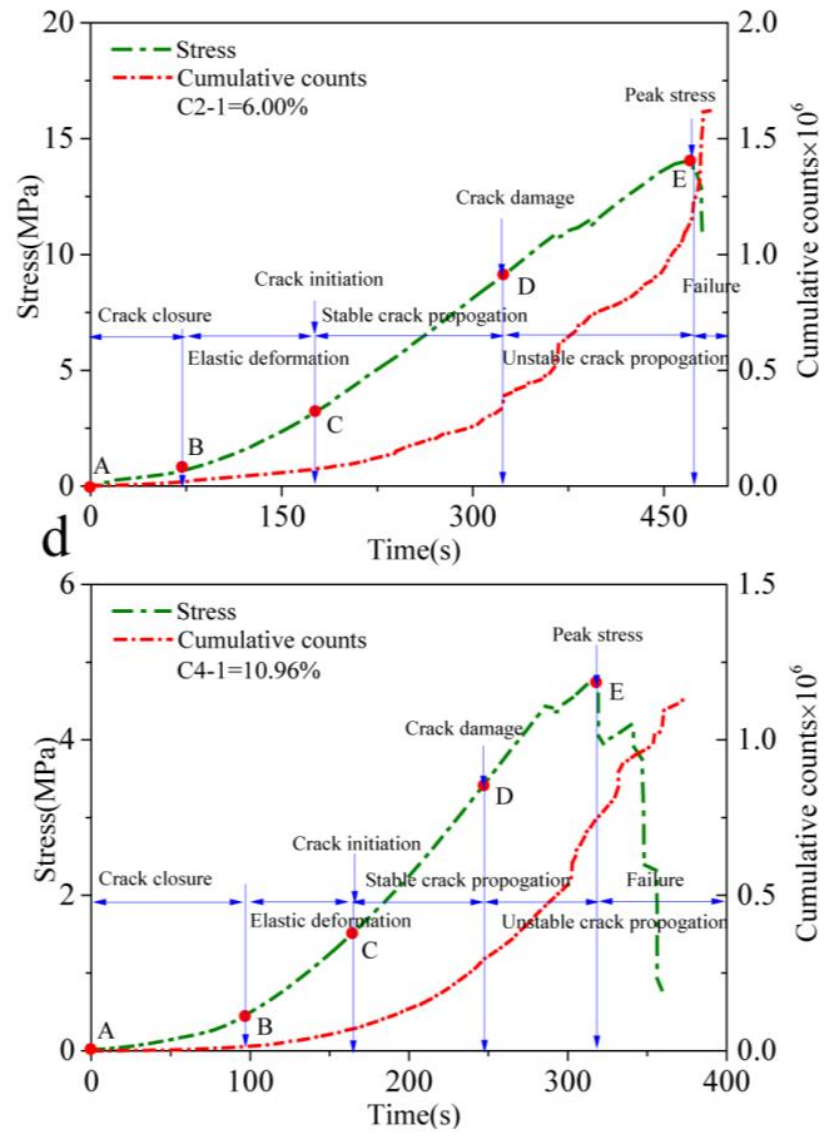

Fig. 9 Water effect on stages of crack propagation based on variations of stress and cumulative counts with time (a) C1-1 (b) C2-1(c)

\section{C3-1 (d) C4-1}

As shown in Fig.10, the cumulative AE counts decrease as moisture content increase. Water fills the pores and weakens contacts between the particles, thereby reducing the strength and cohesion of the coal. Therefore, less energy is required to induce cracks, as reflected by the reduction in $\mathrm{AE}$ counts with increasing moisture content. Yao et al. (2015) have also reported that moisture content reduces the AE activity. AE counts are initially low but increased during unstable crack propagation stage. Similar trend is observed for the variations of the slope of the cumulative AE counts with time. After this stage, AE counts substantially increase. The patterns of the cumulative AE count curves are similar to the stress-strain curves for different samples (Fig. 9); therefore, AE activity can provide information on crack development and changes in mechanical properties. Cumulative counts increase rapidly after point $\mathrm{D}$, as reflected by the steeper slope (refer to Fig. 10). The point of peak stress can be determined based on the $\mathrm{AE}$ activity and stress-strain curves.After point $\mathrm{D}$ (unstable crack propagation), wet coal samples release energy and cumulative counts increase rapidly. In contrast, dry coal samples release a large amount of energy, leading to failure and collapse after this point. 


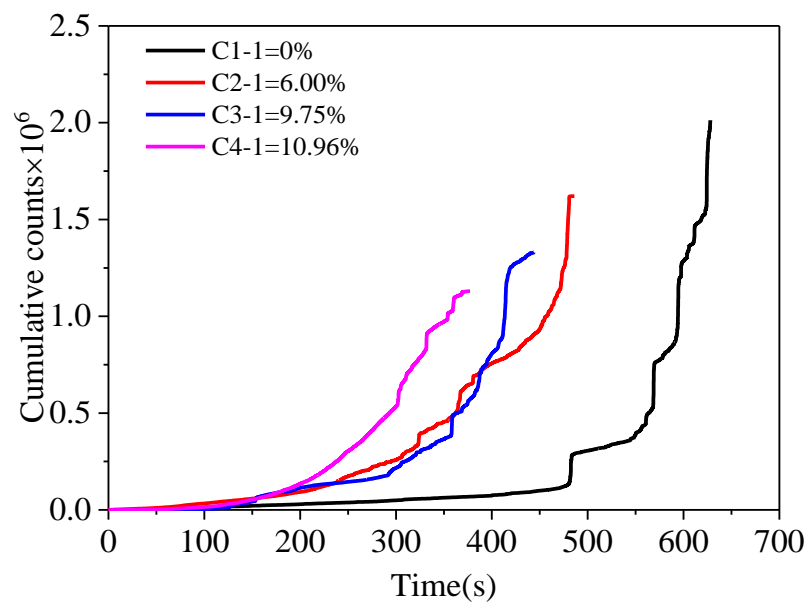

Fig. 10 Variations of cumulative counts with time at different water contents

\subsection{Effect of water on micro tensile/shear cracks and macro tensile/shear failure patterns}

Several studies (Grosse and Ohtsu 2008; Ohtsu et al. 2007) have shown that RA and AF can reflect micro crack patterns in materials; these parameters are defined in the introduction section. Lower AF values and higher RA values normally indicate the occurrence and development of shear cracks, whereas higher AF and lower RA values represent propagation of tensile cracks (Fig. 3c). The procedure adopted for calculation of AF and RA is shown in Appendix 1 (Fig.14). The AE waveform of C1-1 is used as an example to describe the procedure in Fig 14.

Figure 11.1a shows the relationship between AF and RA for the dry coal sample C1-1. Due to the scattering and numerous overlapping points, determination of the location of maximum data density was not possible. The maximum AF value is $1,000 \mathrm{kHz}$, and the maximum RA value is $500 \mathrm{~ms} / \mathrm{v}$. A few outlying points (corresponding to zero time duration) are removed. Numerous points lie along or below the RA-AF line. However, AF and RA are related to the voltage, and thus values overlap and have a diploid relationship (Grosse and Ohtsu 2008); therefore Fig. 11.1a does not reflect an accurate distribution rule of data points .

To demonstrate the distribution of experimental AE data and describe the crack types, we calculated the probability density of experimental RA-AF data using probability density function (Fig. 11.1b). In Fig. 11.1b, areas highlighted in red represent maximum density regions (i.e. areas in which the majority of data is distributed), whereas blue areas indicate zero density. High density areas are located above the diagonal, indicating the dominance of the tensile cracks in the sample C1-1 (refer to Fig. 3) and relatively few shear cracks (note that these tensile and shear cracks are not visible to the naked eye). Based on the relationship between micro-cracks and macro-failure planes (Fig. 4), a large number of tensile cracks and relatively few shear cracks are developed in the dry coal samples under uniaxial compression. As explained in Fig. 4, coal failure is a common effect of both micro- tensile and shear fractures. According to C1-1 presented in Fig. 12, the failure plane of dry coal samples consists of three tensile failure planes and a shear surface.

A large number of tensile cracks and some shear cracks also appear in sample C2-1 (Fig. 11.2b), as well as three tensile failure planes and one shear plane (C2-1 in Fig. 12). In sample C3-1, the number of shear cracks 
increases consistently and is nearly equal to the number of tensile cracks. The final failure process for this sample (C3-1 in Fig. 12) is due to a combination of tensile and shear planes. Figure 11.4b shows that the majority of cracks in the saturated coal sample (C4-1) are shear cracks, and lesser tensile cracks develop. However, the failure process for C4-1 is characterized as typical shear failure, and there is no tensile failure plane effect (only one shear failure plane; C4-1 in Fig.12).
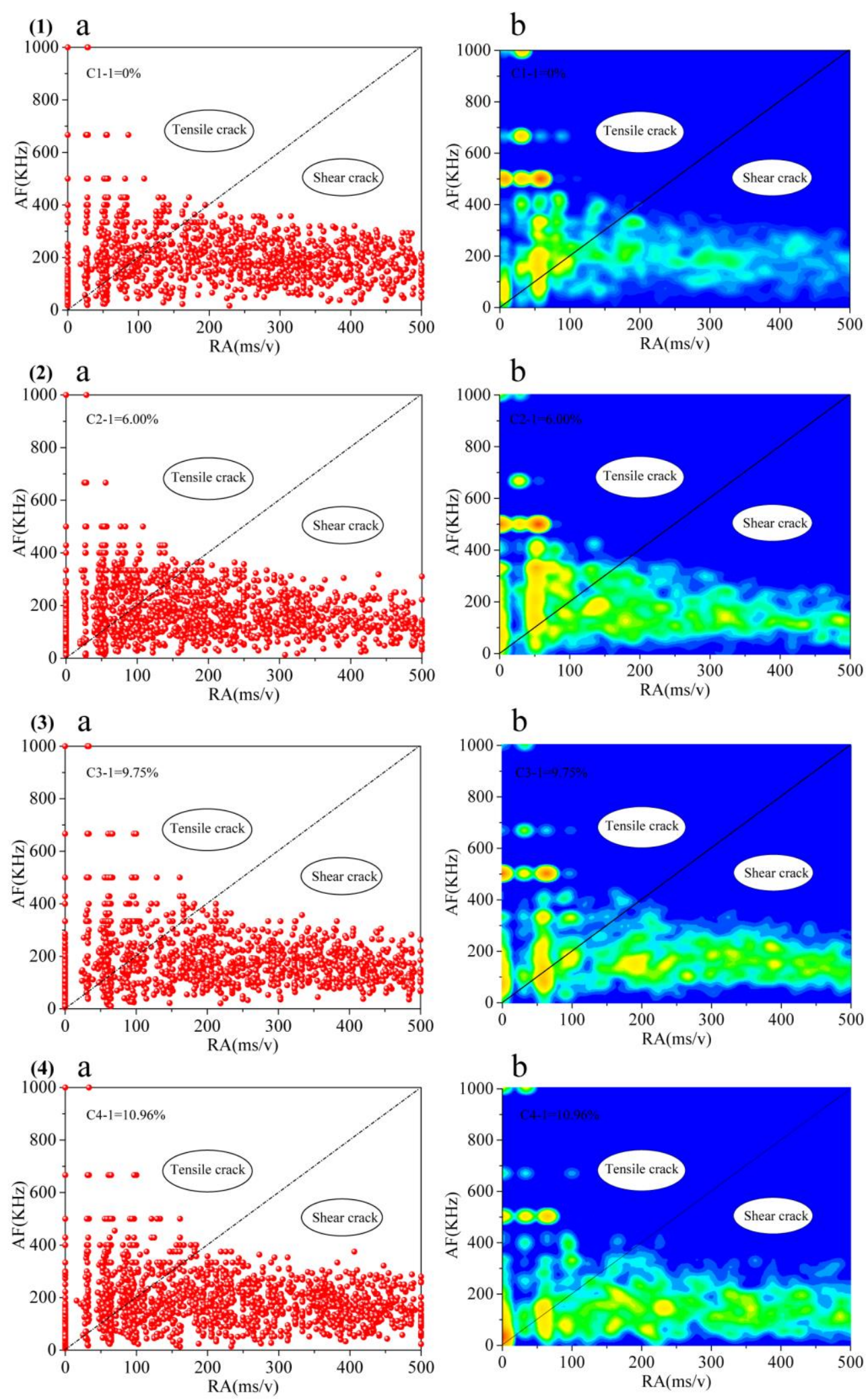

Fig. 11 Coal sample group C1: a) RA-AF relationship; b) Probability density map for RA-AF. 1) C1-1, 2) C2-1, 3) C3-1, 4) C4-1; 
this figure only reflects micro-tensile and shear cracks.

Tensile stress forms cracks that can rapidly develop (Jaeger et al. 2009), causing coal to suddenly breaks and emits strong acoustic signals. Some coal samples can collapse into small blocks and form macro-tensile failure planes, such as in C1-3 in Fig. 12. The size of tensile cracks differs from the amount and intensity of released energy. Shear cracks occur along internal micro-joints and weak surfaces, and shear failure is mainly caused by X-shaped conjugate shear (macro) crack planes and single-plane (macro) shear crack planes (e.g., Fig. 11.4c). Note that, we also refer to macro-crack planes as failure planes.
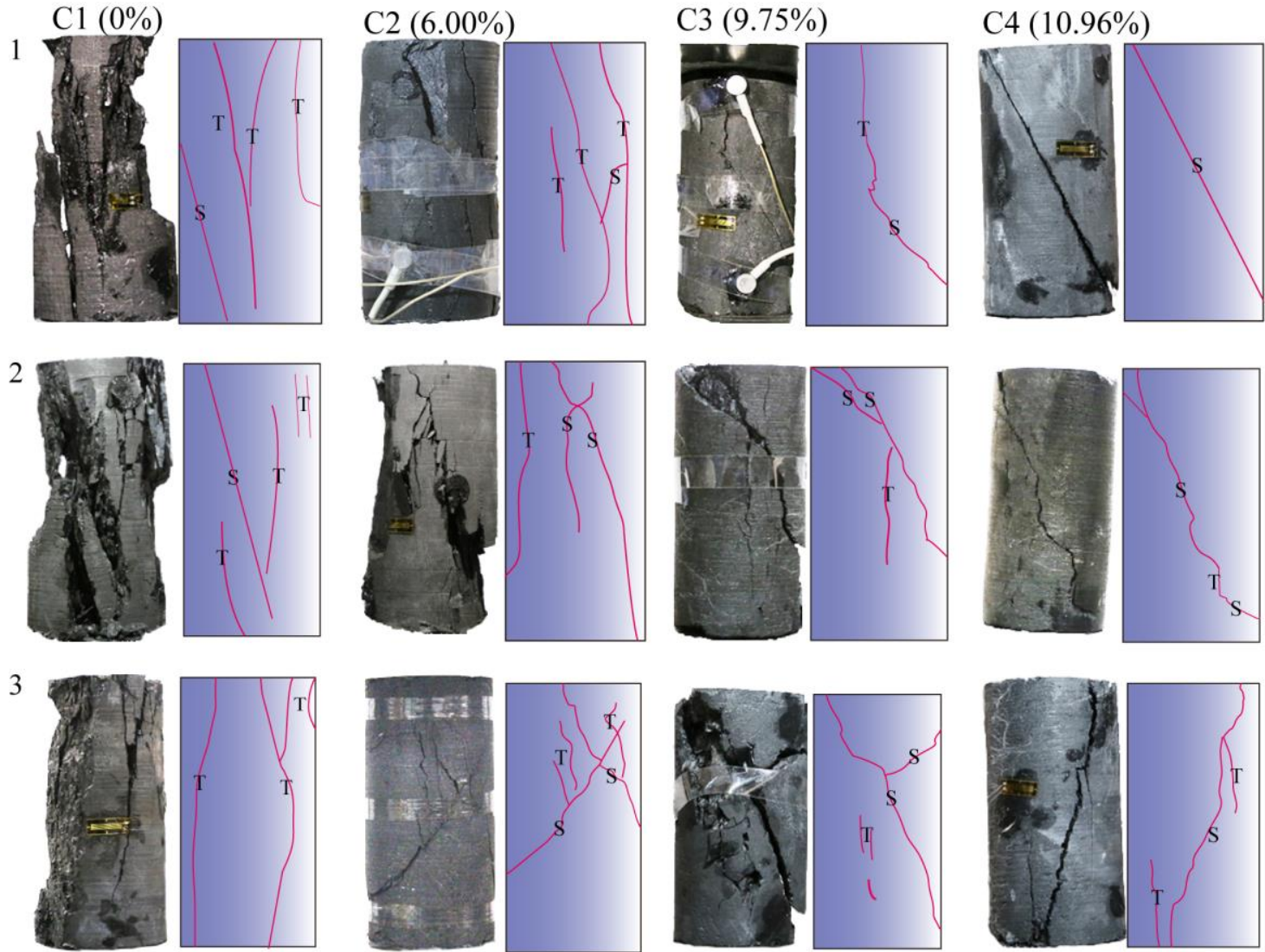

Fig. 12 Failure modes (planes) for all coal sample groups, C1, C2 and C3

Based on the discussion above and Figure 12, the elastic modulus of coal samples with numerous micro-fractures is directly related to the coefficient of friction on the fracture surface. A sufficiently large coefficient will inhibit slip on the crack surface, reduce slipping speed, and increase roughness. The coefficient of friction decreases and movement along cracks is less constrained in coal with higher moisture content, resulting in decreased elastic modulus and risk of shear failure (Eberhardt et al. 1999; Zhang and Gao 2015; Zong et al. 2016), as water reduces contact and alters connections between the particles. Water can cause hydrolysis of organic substances in coal (Zou and Li 2015), catalyze chemical reactions especially under the effect of warm water in deep-mining, or cause complex physical and chemical interactions that reduce the internal adhesion strength and friction coefficient. Such effects are due in part to hydroxyl ions that bind with coal, and consequently alter its microstructure and mechanical properties (Hashiba and Fukui 2014; Xu et al. 2015; Yu et al. 2015). Therefore, coal samples with high moisture content are more likely to show shear failure than dry samples. The failure modes shown in Figure 12 are distinguished as tensile crack planes or shear crack planes (labeled as $\mathrm{T}$ or $\mathrm{S}$ ). We 
quantify the relationship between tensile and shear failure planes using the length of planes (Table 3, Fig. 13). As water content increased, the proportion of tensile failure planes decreased and shear failure increased. Nevertheless, the problem is that only calculating the length of shear/tension failure planes is still not very accuracy. There should be further investigated via AE location and energy analysis in the future.

Table 3 Distribution of tensile and shear failure planes (unit of length: $\mathrm{mm}$ )

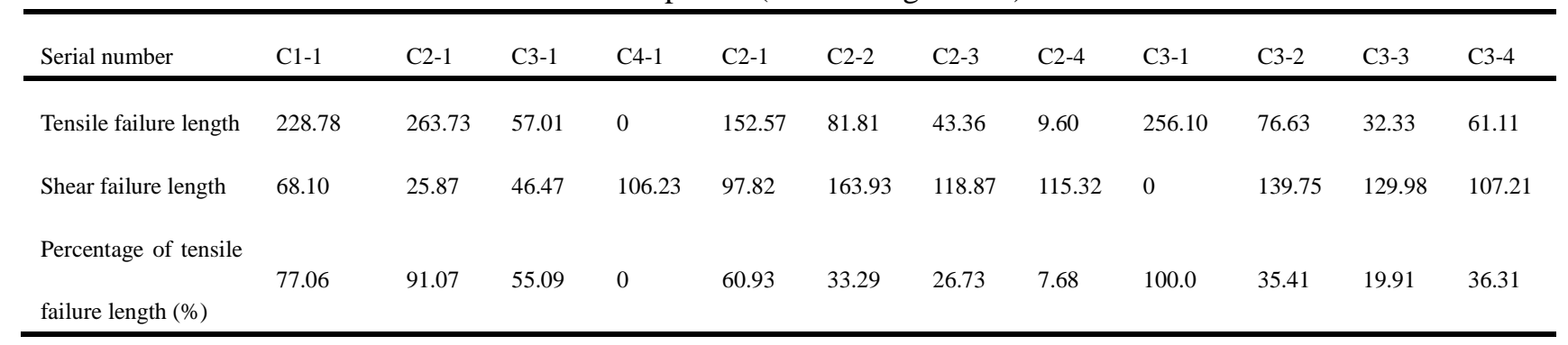

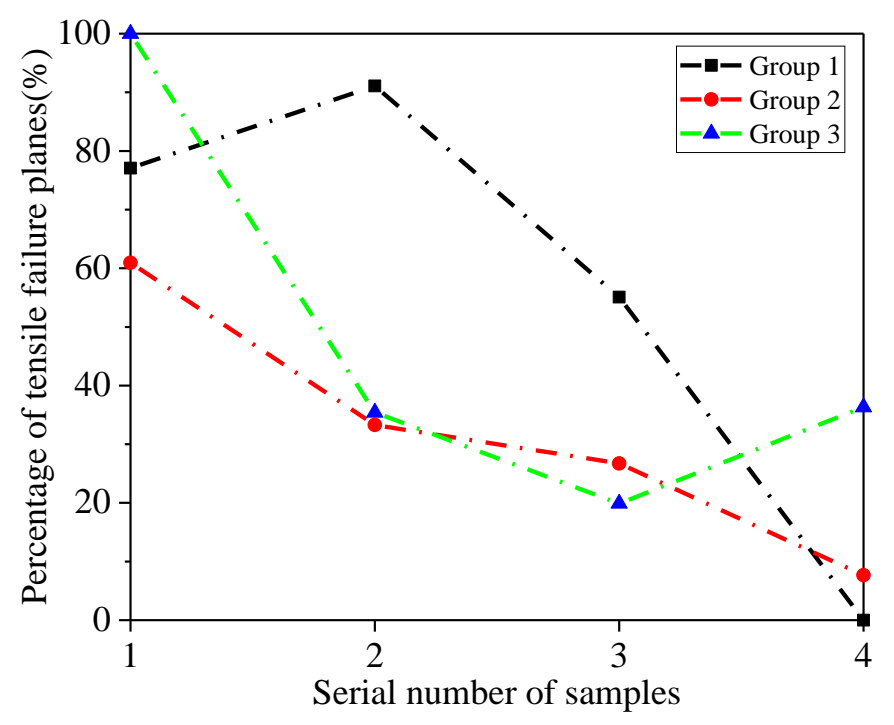

Fig. 13 Percentage of tensile failure planes subjected to total failure planes

\section{Conclusions}

In this paper, the effects of water on crack propagation and failure modes of fractured rock (coal) have been studied based on a series of experimental characterizations (i.e. AE, XRD, SEM and MIP). For the first time, the pseudo-first order kinetic model has been introduced to describe the water absorption of coal. New insights into the effects of water intrusion on micro-tensile/shear cracks and macro tensile/shear failure modes are presented based on the results of our experimental investigation. We have shown that the AE activity mainly occur after point $\mathrm{D}$ (crack damage threshold) with a large amount energy releasing, regardless of the water content. At the micro-level, tensile cracks play a dominant role in the formation of micro-cracks under uniaxial stress. As the moisture content increases, the number of micro-tensile cracks decreases, whereas micro-shear cracks increase. From a macro scale, the coal failure and collapse decrease as water content increases. Rising water level reduces the tensile failure planes as well as the percentage of tensile failure planes versus total failure planes. Under the conditions of the tests carried out, increasing water content promotes the possibility of shear failure in coal. Thus, even if cracks are formed by the local micro tensile and shear stress, increasing water content can elevate the proportion of micro-shear cracks and increase the possibility of macro-shear failure. The probability density 
function proposed is a novel approach in analysing the discrete and irregular RA-AF points and provides improved understanding of the micro tensile/shear cracks in heterogeneous and anisotropic coal, developed through the auxiliary experimental methods (XRD, SEM and MIP).

\section{Acknowledgement}

This work financially supported by "the Fundamental Research Funds for the Central Universities" (No 2018XKQYMS10) are gratefully acknowledged.

\section{References}

Aggelis, D.G. 2011. Classification of cracking mode in concrete by acoustic emission parameters. Mechanics Research Communications, 38, 153-157, doi: 10.1016/j.mechrescom.2011.03.007.

Aggelis, D.G., Kordatos, E.Z. \& Matikas, T.E. 2011. Acoustic emission for fatigue damage characterization in metal plates. Mechanics Research Communications, 38, 106-110, doi: 10.1016/j.mechrescom.2011.01.011.

Aggelis, D.G., Mpalaskas, A.C., Ntalakas, D. \& Matikas, T.E. 2012. Effect of wave distortion on acoustic emission characterization of cementitious materials. Construction and Building Materials, 35, 183-190, doi: 10.1016/j.conbuildmat.2012.03.013.

Azizian, S. 2004. Kinetic models of sorption: a theoretical analysis. J Colloid Interface Sci, 276, 47-52, doi: 10.1016/j.jcis.2004.03.048.

Chen, L., Chen, W., Chen, Y., Benyamin, L. \& Li, A. 2014. Investigation of Hydraulic Fracture Propagation Using a Post-Peak Control System Coupled with Acoustic Emission. Rock Mechanics and Rock Engineering, 48, 1233-1248, doi: 10.1007/s00603-014-0620-y.

Chen, T., Yao, Q., Wei, F., Chong, Z., Zhou, J., Wang, C. \& Li, J. 2017. Effects of water intrusion and loading rate on mechanical properties of and crack propagation in coal-rock combinations. Journal of Central South University, 24, 423-431, doi: 10.1007/s11771-017-3444-6.

Cho, N., Martin, C.D. \& Sego, D.C. 2007. A clumped particle model for rock. International Journal of Rock Mechanics and Mining Sciences, 44, 997-1010, doi: 10.1016/j.ijrmms.2007.02.002.

Committee, R.T. 2010. Recommendation of RILEM TC 212-ACD: acoustic emission and related NDE techniques for crack detection and damage evaluation in concrete. Materials and Structures, 43, 1183-1186.

Eberhardt, E., Stead, D., Stimpson, B. \& Read, R. 1998. Identifying crack initiation and propagation thresholds in brittle rock. Canadian Geotechnical Journal, 35, 222-233.

Eberhardt, E., Stimpson, B. \& Stead, D. 1999. Effects of grain size on the initiation and propagation thresholds of stress-induced brittle fractures. Rock Mechanics and Rock Engineering, 32, 81-99.

Fairhurst, C. \& Hudson, J. 1999. Draft ISRM suggested method for the complete stress-strain curve for intact rock in uniaxial compression. International Journal of Rock Mechanics and Mining Sciences, 36, 279-289.

Farhidzadeh, A., Mpalaskas, A.C., Matikas, T.E., Farhidzadeh, H. \& Aggelis, D.G. 2014. Fracture mode identification in cementitious materials using supervised pattern recognition of acoustic emission features. Construction and Building Materials, 67, 129-138, doi: 10.1016/j.conbuildmat.2014.05.015.

Farhidzadeh, A., Salamone, S. \& Singla, P. 2013. A probabilistic approach for damage identification and crack mode classification in reinforced concrete structures. Journal of Intelligent Material Systems and Structures, 24, 1722-1735, doi: 10.1177/1045389x13484101.

Grosse, C.U. \& Ohtsu, M. 2008. Acoustic emission testing. Springer Science \& Business Media.

Hashiba, K. \& Fukui, K. 2014. Effect of Water on the Deformation and Failure of Rock in Uniaxial Tension. Rock Mechanics and Rock Engineering, 48, 1751-1761, doi: 10.1007/s00603-014-0674-X.

He, M., L. Ribeiro, e.S., Miranda, T. \& Zhu, G. 2015. Rockburst laboratory tests database - Application of data mining techniques. Engineering Geology, 185, 116-130, doi: 10.1016/j.enggeo.2014.12.008.

He, M., Xuena, J., M, C., E, L. \& Luís, S. 2012. Experimental study of rockbursts in underground quarrying of Carrara marble. International Journal of Rock Mechanics and Mining Sciences, 52, 1-8.

Hoek, E. \& Bieniawski, Z. 1965. Brittle fracture propagation in rock under compression. International Journal of Fracture Mechanics, 1, 137-155.

Huang, B. \& Liu, J. 2013. The effect of loading rate on the behavior of samples composed of coal and rock. International Journal of Rock Mechanics and Mining Sciences, 61, 23-30, doi: 10.1016/j.ijrmms.2013.02.002.

Jaeger, J.C., Cook, N.G. \& Zimmerman, R. 2009. Fundamentals of rock mechanics. John Wiley \& Sons, London. 
Jones, M.L., Kalmanovitch, D.P., Steadman, E.N., Zygarlicke, C.J. \& Benson, S.A. 1992. Application of SEM techniques to the characterization of coal and coal ash products. Advances in coal spectroscopy. Springer, 1-27.

Kencanawati, N.N., Iizasa, S. \& Shigeishi, M. 2012. Fracture process and reliability of concrete made from high grade recycled aggregate using acoustic emission technique under compression. Materials and Structures, 46, 1441-1448, doi: 10.1617/s11527-012-9986-z.

Khazaei, C., Hazzard, J. \& Chalaturnyk, R. 2015. Damage quantification of intact rocks using acoustic emission energies recorded during uniaxial compression test and discrete element modeling. Computers and Geotechnics, 67, 94-102, doi: 10.1016/j.compgeo.2015.02.012.

Kordatos, E.Z., Aggelis, D.G. \& Matikas, T.E. 2012. Monitoring mechanical damage in structural materials using complimentary NDE techniques based on thermography and acoustic emission. Composites Part B: Engineering, 43, 2676-2686, doi: 10.1016/j.compositesb.2011.12.013.

Li, Z., Lin, B., Hao, Z., Gao, Y., Liu, F., 2013. Fractal characteristics of porosity for porous media in coal mass. J. Min. Saf. Eng. 3, 437-442 1673-3363-(2013)03-0437-06.

Lyu, Q., Pg, R., Long, X., Kang, Y. \& Huang, M. 2015. Effects of coring directions on the mechanical properties of Chinese shale. Arabian Journal of Geosciences, 8, 10289-10299, doi: 10.1007/s12517-015-1977-2.

Martin, C.D. 1993. The strength of massive Lac du Bonnet granite around underground openings.

Masahiro, S., Hidekazu, S. \& Masaru, S. 1988. Hypocenter distributions of AE in coal under uniaxial compression. Journal of the Mining and Metallurgical Institute of Japan, 104, 163-168.

Meng, F., Zhou, H., Zhang, C., Xu, R. \& Lu, J. 2014. Evaluation Methodology of Brittleness of Rock Based on Post-Peak Stress-Strain Curves. Rock Mechanics and Rock Engineering, 48, 1787-1805, doi: 10.1007/s00603-014-0694-6.

Mogi, K. 2007. Experimental rock mechanics. CRC Press.

NDRC \& NEB. 2016. The development of coal industry in the "13th Five-Year" plan.

Nor, M., Noorsuhada, Ibrahim, A., Muhamad Bunnori, N. \& Mohd Saman, H. 2013. Acoustic emission signal for fatigue crack classification on reinforced concrete beam. Construction and Building Materials, 49, 583-590, doi: 10.1016/j.conbuildmat.2013.08.057.

Ohno, K. \& Ohtsu, M. 2010. Crack classification in concrete based on acoustic emission. Construction and Building Materials, 24, 2339-2346, doi: 10.1016/j.conbuildmat.2010.05.004.

Ohtsu, M., Isoda, T. \& Tomoda, Y. 2007. Acoustic emission techniques standardized for concrete structures. Journal of Acoustic Emission, 25, 21-32.

Peng, S.S. 2013. Coal mine ground control. China University of Mining and Technology Press, Xuzhou.

Ranjith, P., Fourar, M., Pong, S., Chian, W. \& Haque, A. 2004. Characterisation of fractured rocks under uniaxial loading states. International Journal of Rock Mechanics and Mining Sciences, 41, 361.

Ranjith, P.G., Jasinge, D., Song, J.Y. \& Choi, S.K. 2008. A study of the effect of displacement rate and moisture content on the mechanical properties of concrete: Use of acoustic emission. Mechanics of Materials, 40, 453-469, doi: 10.1016/j.mechmat.2007.11.002.

Terzaghi, K., Peck, R.B. \& Mesri, G. 1996. Soil mechanics in engineering practice. John Wiley \& Sons.

Vishal, V., Ranjith, P. \& Singh, T. 2015. An experimental investigation on behaviour of coal under fluid saturation, using acoustic emission. Journal of Natural Gas Science and Engineering, 22, 428-436.

Woo, S.-C., Kim, J.-T., Kim, J.-Y. \& Kim, T.-W. 2014. Correlation of fracture processes and damage mechanisms of armor structural materials under high strain rates with acoustic emission characteristics. International Journal of Impact Engineering, 63, 29-42, doi: 10.1016/j.ijimpeng.2013.07.007.

$\mathrm{Xu}$, H., Liu, J., Wang, L., Yang, B. \& Yang, H. 2015. The weakening effect of hydrostatic pressure on rock mass of different lithology. Environmental Earth Sciences, 74, 2489-2497, doi: 10.1007/s12665-015-4255-4.

Yang, S.-Q., Tian, W.-L. \& Ranjith, P.G. 2017. Experimental Investigation on Deformation Failure Characteristics of Crystalline Marble Under Triaxial Cyclic Loading. Rock Mechanics and Rock Engineering, 50, 2871-2889, doi: 10.1007/s00603-017-1262-7.

Yao, Q., Chen, T., Ju, M., Liang, S., Liu, Y. \& Li, X. 2016. Effects of Water Intrusion on Mechanical Properties of and Crack Propagation in Coal. Rock Mechanics and Rock Engineering, 49, 4699-4709, doi: 10.1007/s00603-016-1079-9.

Yao, Q., Li, X., Zhou, J., Ju, M., Chong, Z. \& Zhao, B. 2015. Experimental study of strength characteristics of coal specimens after water intrusion. Arabian Journal of Geosciences, 8, 6779-6789, doi: 10.1007/s12517-014-1764-5.

Yu, Z., Zhang, L., Jiang, P., Papelis, C. \& Li, Y. 2015. Study on water-rock interactions of trace elements in groundwater with leaching experiments. Ground Water, 53 Suppl 1, 95-102, doi: 10.1111/gwat.12182.

Zhang, Z. \& Gao, F. 2015. Experimental investigation on the energy evolution of dry and water-saturated red sandstones. International Journal of Mining Science and Technology, 25, 383-388.

Zong, Y., Han, L., Wei, J. \& Wen, S. 2016. Mechanical and damage evolution properties of sandstone under triaxial compression. International Journal of Mining Science and Technology, 26, 601-607.

Zou, J. \& Li, S. 2015. Theoretical solution for displacement and stress in strain-softening surrounding rock under hydraulic-mechanical coupling. Science China Technological Sciences, 58, 1401-1413, doi: 
10.1007/s11431-015-5885-1

Zygarlicke, C. \& Steadman, E. 1990. Advanced SEM techniques to characterize coal minerals. Scanning Microscopy, 4, 579-590. 


\section{Appendix 1}

a

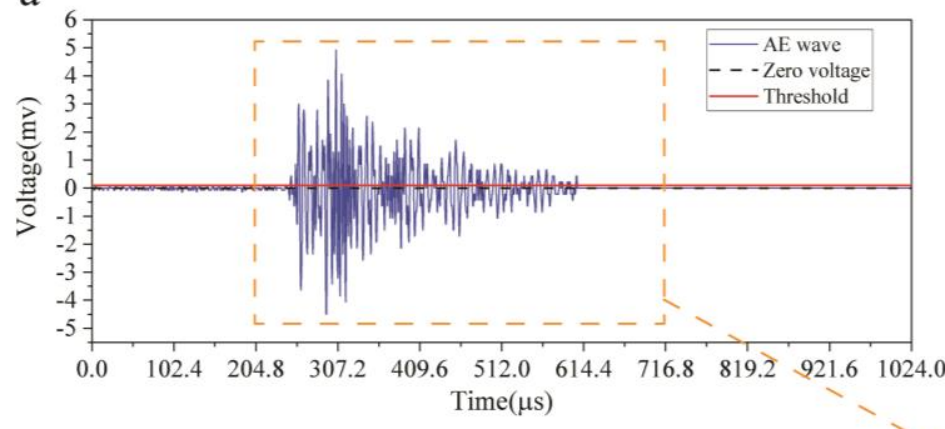

c

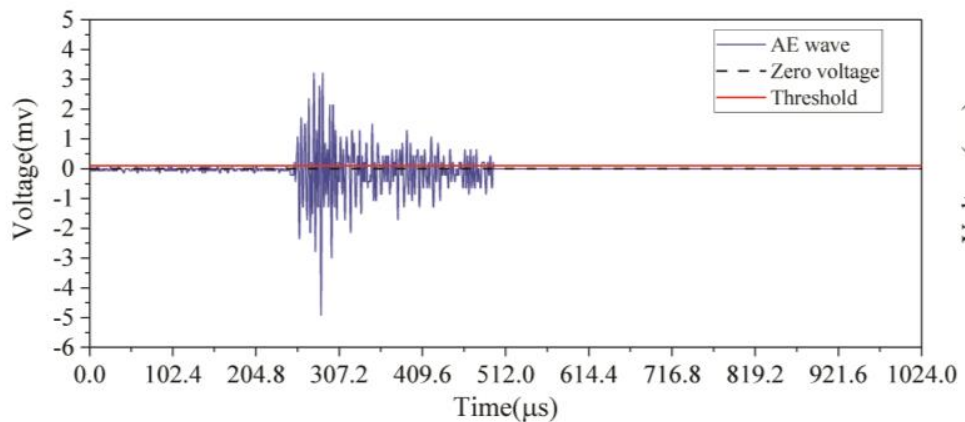

b

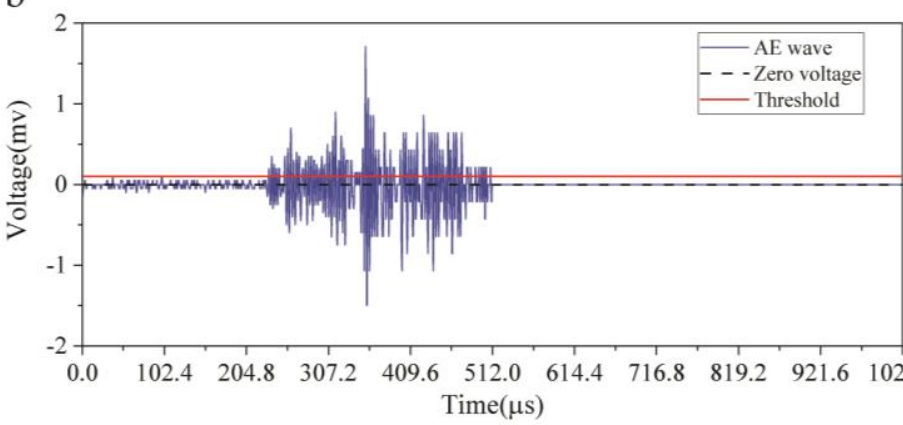
d

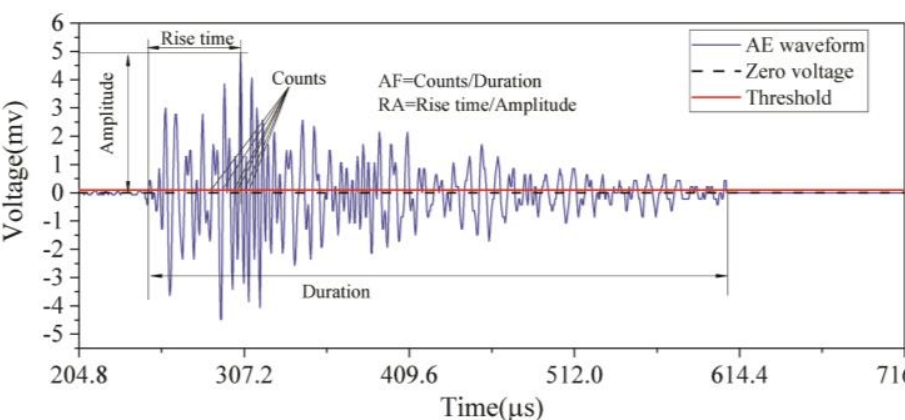

Fig. 14 AE waveforms analysis (using C1-1 as an example, sampling frequency $2 \mathrm{MHz}$ ): starting time of wave a)84.1173355, b)160.0884583, c)377.1946385, d) magnified portion of wave (a) (unit: second). 
The method for analyzing the RA and AF through AE waveforms is shown in Fig.14. By considering, the C1-1 as an example, three AE waves (numbered as a, b, c) have been randomly selected from the waveform files. In order to explain the calculation approach, Fig.14d has been developed which is the extracted waveform from wave (a) with a time period of 204.8 716.8 $\mu$ s (the corresponding absolute time of this period of waveform time in the entire test should be plus staring time, i.e. 84.1173355 seconds in this case). It is noted that the counts are the number of times when the signal amplitude exceeds the threshold (see Fig. 3a). In Fig. 14d, we have not pointed out all the counts using black lines manually and the counts can be easily derived using simple programming. All the results obtained from Fig.14 have been presented in Table 4, which are the same with the data detected through AEwin software.

Table 4 the RA and AF calculated using the AE waveforms from Fig.14

\begin{tabular}{ccccccc}
\hline Waveform & rise time $(\mathrm{us})$ & amplitude $(\mathrm{mv})$ & counts & duration $(\mathrm{us})$ & $\mathrm{AF}(\mathrm{kHz})$ & $\mathrm{RA}(\mathrm{ms} / \mathrm{v})$ \\
\hline $\mathrm{a}(\mathrm{d})$ & 57 & 4.83 & 69 & 359 & 191.8 & 11.9 \\
$\mathrm{~b}$ & 124 & 1.62 & 90 & 281 & 320.0 & 76.6 \\
$\mathrm{c}$ & 35 & 3.13 & 55 & 246 & 223.5 & 11.4 \\
\hline
\end{tabular}

